\title{
In-vitro development and degeneration of stromal cells from the uterus of the rat at three stages of pregnancy
}

\author{
D. F. Pippard*
}

Physiological Laboratory, University of Cambridge, Downing Street, Cambridge CB2 3EG, U.K.

\begin{abstract}
Summary. On Days 6,11 or 16 of pregnancy, endometrial tissue (Day 6) or decidual tissue (Days 11 and 16) were removed from rat uteri, dissociated into single cells and grown in culture. At intervals during the culture period, the cells were examined and the cell density was calculated. The cells from Days 11 and 16 of pregnancy were similar in appearance, being very large and flattened. Initially, cells from Day 6 were much smaller, but showed an increase in size and came to resemble cells from the later stages of pregnancy. Growth curves for cells from each of the three stages of pregnancy over the first 16 days of culture differed. Cells from Day 6 of pregnancy increased exponentially in number. In cultures of cells from Day 11 , cell numbers were stable, and in cultures of cells from Day 16, an exponential decline was seen. Cells from Days 6 and 11 of pregnancy were cultured for 42 days, by which time only a few cells remained viable. Cultures of cells from Day 16 degenerated within 3 weeks.

These results indicate that, in vivo, decidual cells are not controlled solely by a 'programmed lifespan'. Changes occurring during pregnancy, however, limit the potential of the cells for division and survival in culture.
\end{abstract}

\section{Introduction}

During pregnancy in many mammalian species, the uterine stroma differentiates to form decidual cells. In rodents particularly, this decidual cell reaction is very marked and, during the week after implantation, hypertrophy and division of the endometrial cells results in the formation of a thick capsule around the embryo (Krehbiel, 1937; Bridgeman, 1948; Stewart \& Peel, 1978; Welsh \& Enders, 1983). During the second half of pregnancy, the decidua regresses. Cell death occurs initially in the antimesometrial decidua and spreads rapidly throughout this region so that by the 3rd week of pregnancy, only a few cell fragments remain adhering to the trophoblast cells and Reichert's membrane (Bulmer \& Dickson, 1961; Dickson, 1979; Welsh \& Enders, 1983, 1985). Degeneration of the mesometrial decidua occurs later: the tissue gradually thins over the last week of pregnancy and is lost with the placenta at parturition (Scott \& Pendergrass, 1981).

Decidual differentiation can be induced artificially by a variety of experimental stimuli in pseudopregnant and hormonally primed ovariectomized rats and mice (e.g. Finn \& Keen, 1962; Hetherington, 1968; Tobert, 1976). The resultant deciduomata have a limited lifespan of about 2 weeks and regression follows the pattern of that of the decidua of pregnancy (Krehbiel, 1937; Velardo et al., 1953). The similarity in structure, development and regression of naturally and artificially induced decidual tissue has led to the suggestion that the decidua may be controlled by an inherent 'programmed lifespan' rather than being under the control of the embryo or other extra-decidual factors (Vladimirsky et al., 1977).

*Present address: National Poisons Information Service, Poisons Unit, New Cross Hospital, Avonley Road, London SE14 SER, U.K. 
Elucidating the control of decidual tissue in vivo is difficult because of the many changes in the physical and hormonal environment of the decidua during pregnancy. By limiting the variable factors, in-vitro techniques provide a valuable means of investigating some of the questions of decidual control. Several workers have made in-vitro studies of dissociated decidual and endometrial tissue obtained from rats and mice undergoing a variety of experimental treatments designed to induce decidualization (Vladimirsky et al., 1977; Sananes et al., 1978; Bell \& Searle, 1981). These workers have focussed attention on the earliest stages of differentiation and have demonstrated that the cells undergo morphological changes in vitro (development of binucleate cells, accumulation of large quantities of filamentous material) characteristic of decidualization in vivo (Jollie \& Bencosme, 1965; O'Shea et al., 1983; Welsh \& Enders, 1985). Cell division is seen during the first few days of culture but dead cells are observed after about 1 week and degeneration of the cultures is complete after 14-28 days. There is no information on the morphology of fully differentiated decidual cells of pregnancy in vitro.

In this study, cells taken at the start of differentiation, when the decidua was fully differentiated, or when it was regressing were cultured in vitro. The morphology of the cells from the three stages of pregnancy was compared and the cells were examined to determine their growth potential when released from any extra-decidual factors influencing them in vitro.

\section{Materials and Methods}

\section{Animals and tissues}

CFHB rats from the laboratory colony were used. Females were housed 6 to a cage and males were housed individually, under conditions of $12 \mathrm{~h}$ light, $12 \mathrm{~h}$ dark (lights on at $08: 00 \mathrm{~h}$ ) and a temperature of $25^{\circ} \mathrm{C}$. Food (Diet no. 3, Special Diet Services Ltd, Witham, Essex, U.K.) and water were provided ad libitum.

For mating, 2-4 females were placed with each stud male and left overnight. Vaginal smears were taken the following morning and examined for the presence of spermatozoa; the morning of finding a sperm-positive smear was designated Day 1 of pregnancy. On Day 6,11 or 16 of pregnancy, the animals were anaesthetized lightly with ether and killed by cervical dislocation. The uterine horns were dissected out, cleared of adherent fat and mesentery, rinsed in sterile Hanks' saline and opened along the antimesometrial side.

To obtain endometrial tissue from Day 6 of pregnancy, the inner surfaces of the uterine horns were gently scraped with a scalpel blade: histological examination showed that this method effectively separated the endometrium from the myometrium. On Days 11 and 16 of pregnancy, the conceptuses and decidua were gently eased from the uterine horns, the embryonic and decidual tissues were separated and the decidual tissue was rinsed in Hanks' saline.

The tissue was minced, weighed, placed in a $1 \%$ solution of trypsin (porcine type II, Sigma Chemical Co. Ltd, Poole, Dorset, U.K.) in sterile Hanks' saline $\left(140.0 \mathrm{~mm}-\mathrm{NaCl}_{2}, 5.3 \mathrm{~mm}-\mathrm{KCl}, 0.4 \mathrm{~mm}-\mathrm{Na}_{2} \mathrm{HPO}_{3}, 0.4 \mathrm{~mm}-\mathrm{KH}_{2} \mathrm{PO}_{4}\right.$, $5.5 \mathrm{~mm}$-glucose, $4.2 \mathrm{mM}-\mathrm{NaHCO}_{3}$ ) and incubated at $37^{\circ} \mathrm{C}$ for $1 \mathrm{~h}$. At the end of the incubation period, the trypsin action was arrested by the addition of $1 \mathrm{ml}$ fetal calf serum (FCS; Flow Laboratories, Irvine, Ayreshire, U.K.) per ml of cell suspension (Vladimirsky et al., 1977). The cell suspension was filtered through 4 layers of sterile gauze to remove any tissue fragments remaining undigested. This resulted in a suspension of single cells plus a few groups of 2-3 cells. The suspension was centrifuged at low speed for $3 \mathrm{~min}$ and the cell pellet thus obtained was resuspended in Dulbecco's modification of Eagles' medium (DMEM, Gibco Ltd, Paisley, Renfrewshire, U.K.) containing 10\% FCS.

\section{Experiments}

Effect of various seeding densities on subsequent survival of cultured cells. Suspensions containing $1.25 \times 10^{4}$, $2.50 \times 10^{4}$ and $5.00 \times 10^{4}$ cells per ml were prepared from decidual tissue obtained on Day 11 of pregnancy. The 35$\mathrm{mm}$ diameter plastic Petri dishes (Sterilin Ltd, Teddington, Middlx, U.K.) were inoculated with $2 \mathrm{ml}$ of suspension, giving 100,50 or 25 cells per $\mathrm{mm}^{2}$. The cells were incubated at $37^{\circ} \mathrm{C}$ in an atmosphere of $5 \% \mathrm{CO}_{2}$ in air. The medium was changed after $24 \mathrm{~h}$ and thereafter every 3 days.

On Days $1,4,7,10,13$ and 16 of culture the plating density (attached cells $/ \mathrm{ml}^{2}$ ) was determined by resuspending and counting the cells. The attached cells were resuspended by incubating the plates at room temperature for 15-30 min in a solution of $0.1 \%$ trypsin and $0.02 \%$ EDTA (BDH Chemicals Ltd, Poole, Dorset, U.K.) in calciumand magnesium-free Hanks' saline. The average of the number of cells on two plates and thus the cell density was determined using a haemocytometer.

Growth curves. After inoculation of 35-mm diameter Petri dishes with 100 cells $/ \mathrm{mm}^{2}$, the cell density on Days 1,4 , $7,10,13$ and 16 of culture was calculated in the manner described above. Duplicate cultures from each day of pregnancy were set up. 
The plating efficiency (number of attached cells expressed as a percentage of the total inoculum size) after $24 \mathrm{~h}$ was determined for each culture. Student's $t$ test was used to analyse the effect of day of explantation on plating efficiency.

Morphological examination. Cell suspensions from Days 6, 11 and 16 of pregnancy were prepared, and 100-mm diameter Petri dishes containing glass coverslips (Chance Propper Ltd, Smithwick, W. Midlands, U.K.) were seeded with 100 cells per $\mathrm{mm}^{2}$.

After $24 \mathrm{~h}$ and weekly thereafter, coverslips with adherent cells were removed, rinsed in Hanks' saline at $37^{\circ} \mathrm{C}$ and placed in warmed fixative: $0.5 \%$ glutaraldehyde (Emscope, Ashford, Kent, U.K.) and 0.2\% formaldehyde (Taab Laboratories, Reading, Berks, U.K.) in 0.15 M-cacodylate buffer (Agar Aids Ltd, Stansted, Essex, U.K.) containing 2 mM-calcium ions. The cells were fixed at $4^{\circ} \mathrm{C}$ overnight, then rinsed and placed in buffer. After staining with $1 \%$ toluidine blue (Taab Laboratories, Reading, Berks, U.K.) in $1 \%$ aqueous borax (Sigma), the coverslips were rinsed and air dried over a warm plate before being mounted, cell side down, in a drop of immersion oil.

\section{Results}

\section{Effect of seeding density}

Cultures of cells explanted on Day 11 of pregnancy and maintained for 16 days showed a slight, but not statistically significant, decline in numbers over the culture period (Fig. 1).

Analysis of the mean cell numbers in each of the cultures over the entire period showed that at no time did the numbers of cells differ significantly from the seeding density ratio of 4:2:1.

\section{Plating efficiency}

The plating efficiency (means \pm s.e.m. of duplicate cultures) of the uterine cells decreased significantly as the period of gestation before explantation increased, being $44 \pm 9 \%$ on Day 6 , $28 \pm 7 \%$ on Day $11(P<0.01)$ and $14 \pm 7 \%$ on Day $16(P<0.01)$.

\section{Growth curves}

The numbers of cells in each culture followed patterns characteristic for each of the three stages of pregnancy considered. Cells derived from Day 6 of pregnancy exhibited an approximately exponential increase in cell numbers, with a cell doubling time of 6 days. A slight decrease in numbers of cells from Day 11 of pregnancy was seen, but this was not significant, while an approximately exponential decline in numbers of cells from Day 16 of pregnancy was observed (Fig. 2).

To check that the exponential rise in cell numbers in cultures from Day 6 of pregnancy was not due to contaminating embryonic tissue, endometrial cells from Day 5 of pregnancy were cultured in the same manner after the uterine horns had been flushed with sterile Hanks' saline to remove the blastocysts. In order to ensure that the flushing procedure was effective, the washings were examined to check for the presence of blastocysts. No significant difference in the plating efficiency was found and the cells showed exponential growth with a similar doubling time (of 5 days).

\section{Morphology of cultured cells}

Cells from Day 6 of pregnancy. At $24 \mathrm{~h}$ after plating, two cell types were observed. The more numerous type consisted of flattened, stellate cells (Fig. 3). Due to the similarity of these cells to previously published descriptions of stromal cells in culture, they were considered to be stromal in origin. The contribution of the stromal cells to the total number of cultured cells was $89 \pm 2 \%$ (s.e.m.) on Day $6,87 \pm 2 \%$ on Day 11 and $25 \pm 4 \%$ on Day 16 . The second type of cell was much smaller and rounded: these were probably leucocytes and will not be considered further.

The majority ( $92 \pm 2 \%$ ) of the cells had a single nucleus: the remainder were binucleate, but no mitotic figures were observed at this stage. On Day 1 of culture, the larger part of the culture dish was bare of cells, but as the culture progressed, a combination of cell division and an increase in area of individual cells gave rise to an incomplete monolayer by Day 7, and by Day 14 to a 


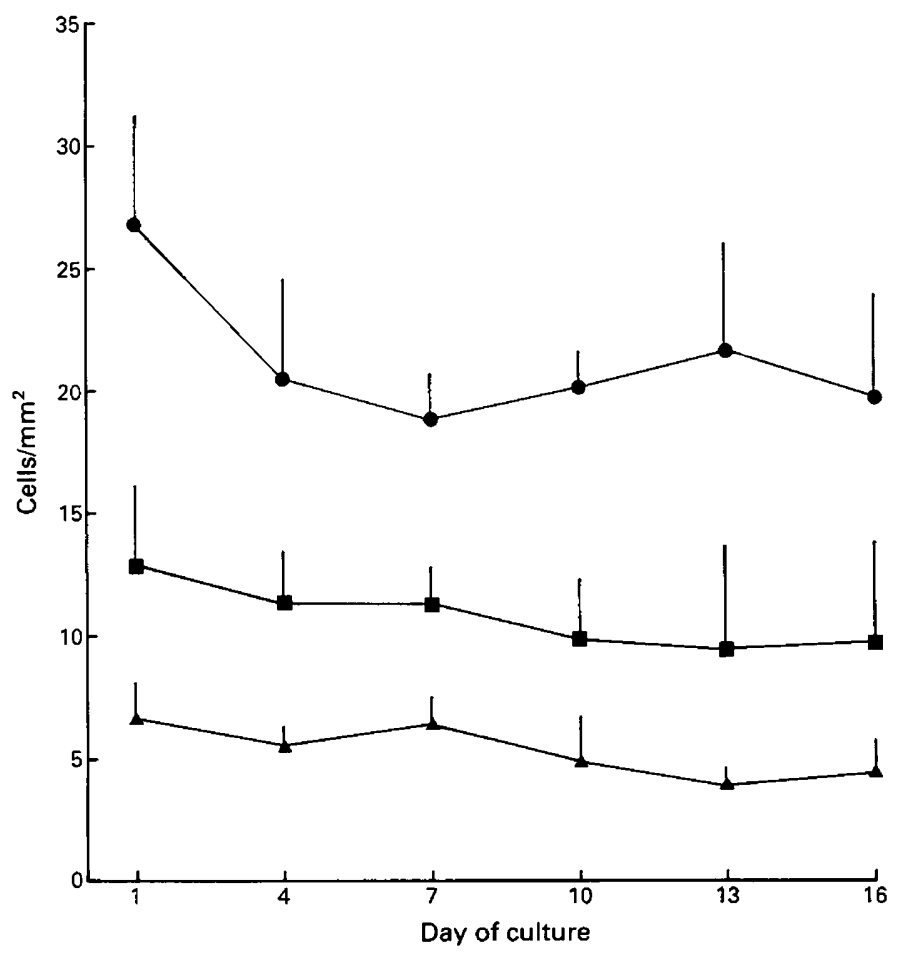

Fig. 1. Effect of seeding density $\left(\boldsymbol{O}=100\right.$ cells $/ \mathrm{mm}^{2} ; \boldsymbol{\theta}=50$ cells $/ \mathrm{mm}^{2} ; \boldsymbol{\Delta}=25$ cells $\left./ \mathrm{mm}^{2}\right)$ on subsequent cell density in cultures of cells from Day 11 of pregnancy. The values are obtained from three duplicate cultures and represent the mean and s.e.m.

number of multilayered areas superimposed on a basal monolayer. Cells in the more densely populated areas differed from those forming the monolayer between them in that the former were less flattened, smaller and more stellate in shape (Fig. 4).

The cell density increased until Day 21 of culture, with cell debris first visible on Day 14 of culture. The cell population declined from Day 21 until the cultures were ended after 42 days. By this time, much of the surface was bare, but those cells remaining appeared to be healthy. Degeneration was seen initially in the more crowded areas of the cultures, but as time went on, dead cells were seen throughout the cultures.

Initially, the cells had round or slightly lobulated nuclei. Over the first 3 weeks in culture, the size and complexity of the nuclei increased greatly, so that, by Day 21 , oval or irregularly shaped, lobulated nuclei were seen. In the less densely populated areas of the cultures, the nuclei were much larger and more lobulated. At every stage the majority of cells (over $90 \%$ ) had a single nucleus, while for the first 3 weeks the remaining cells had two nuclei. On Day 28 of culture, the first cells with 3 nuclei were seen.

An attempt was made to quantify the increase in cell area over the culture period, but the degree of overlap between the cells made this impossible. A comparison of Figs 3 and 4, however, demonstrates the very striking increase in cell size.

Cells from Day 11 of pregnancy. A variety of cell types was seen on the first day of culture. The majority, however, were flattened, stellate cells which were assumed to be of decidual origin. Other cell types included macrophages, leucocytes and trophoblast cells. The distribution and fate of these non-decidual cells is described in detail elsewhere (Pippard, 1987) and only the cells of decidual origin are described here. 


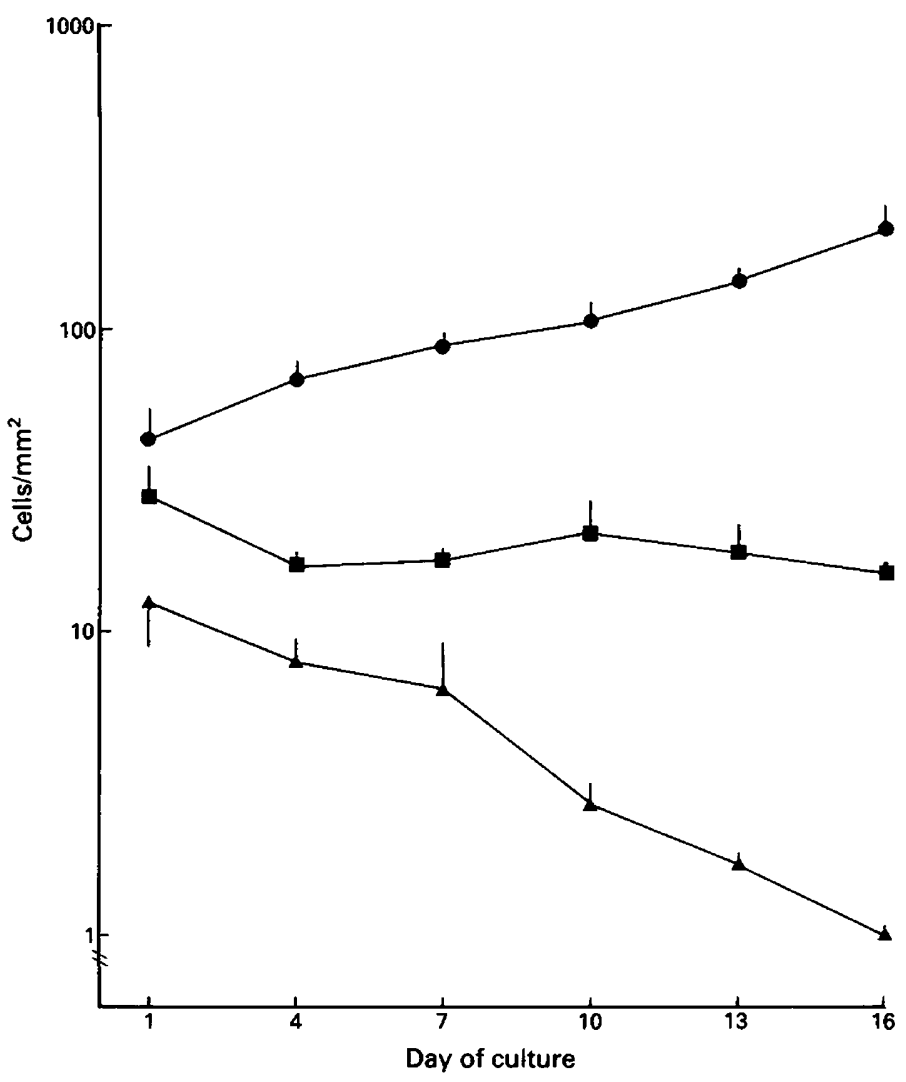

Fig. 2. Mean + s.e.m. cell density in cultures of cells from Days $6(\bullet), 11(\square)$ and $16(\Delta)$ of pregnancy. The values are obtained from two duplicate cultures.

On the first day of culture, cells from Day 11 of pregnancy were larger and had a more irregular shape than those from Day 6; the nuclei were slightly lobulated. Although the majority of cells at this stage were isolated, groups of cells were seen more commonly than in cultures derived from Day 6 of pregnancy (Fig. 5).

By Day 7 of culture, the cells had increased in area. As on Day 1 of culture, the cell density varied from sparse to confluent and the cells tended to be arranged in groups of 10-15 cells, with few isolated cells visible. The nuclei by this stage had increased in size and complexity so that each cell had 1 or 2 oval or lobulated nuclei containing 2-5 clumps of heterochromatin.

Over the remainder of the culture period the cells retained an appearance similar to that on Day 7 of culture, although some further flattening and increase in area was seen (Fig. 6). Cell debris was observed at all stages and a decline in cells numbers was noticeable after Day 21 . Viable cells were still present, however, when the cultures were ended after 42 days.

Cells from Day 16 of pregnancy. As in the culture of cells from Day 11, a variety of cell types was seen. Stellate cells indistinguishable from those seen in cultures of cells from Day 11 of pregnancy were present but contributed a small proportion of the total. The numbers of cells in these cultures declined precipitously and, by Day 21, no cells remained. As with cells from Day 11 of pregnancy, an increase in area of cell and nucleus was seen over the culture period, but in cultures of cells from Day 16 of pregnancy, cells with 3 or 4 nuclei were commonly observed. The nuclei were rounded or lobulated, as in the other culture and again prominant heterochromatin concentrations were seen. 


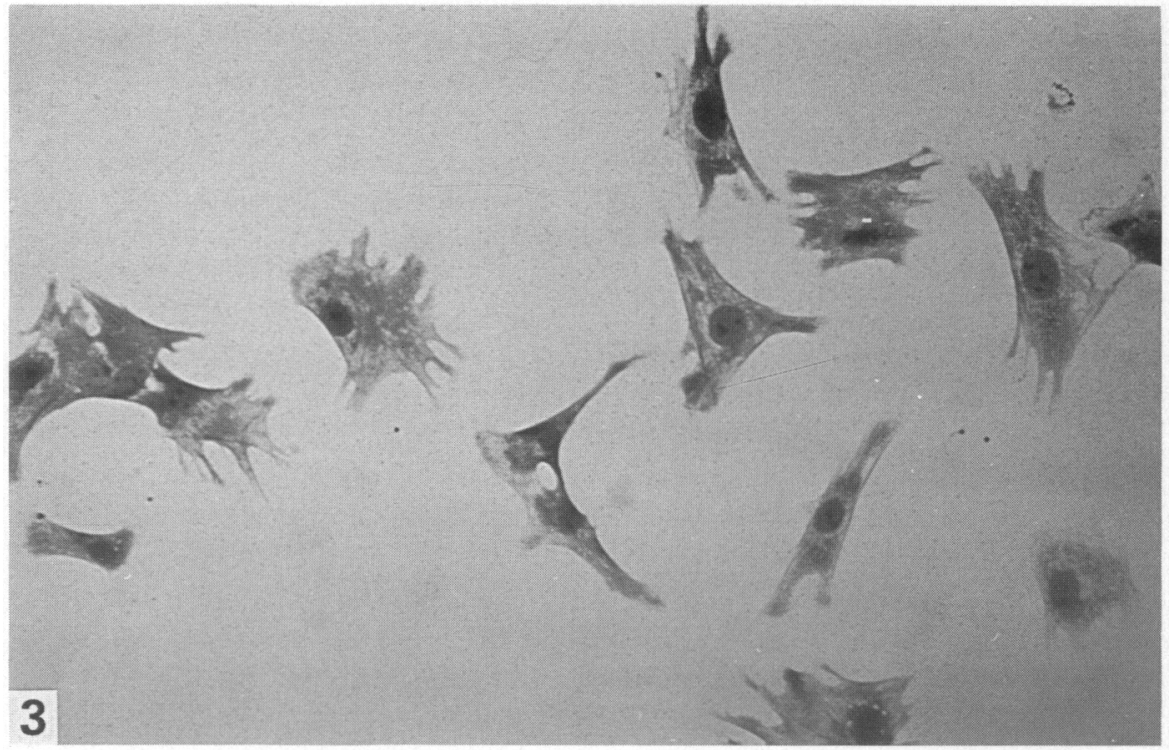

Fig. 3. Cells from Day 6 of pregnancy on Day 1 of culture. The cells are small, have rounded nuclei and are well dispersed. $\times 150$.

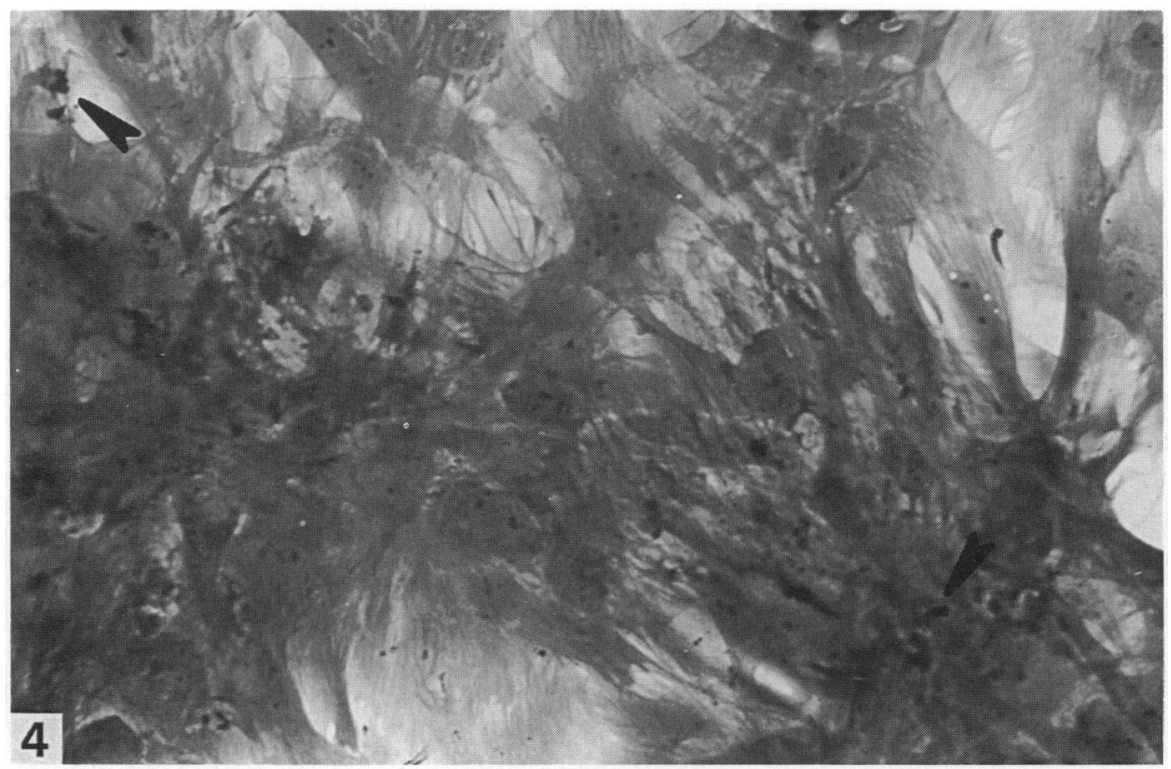

Fig. 4. Cells from Day 6 of pregnancy on Day 14 of culture. The cells in the less densely populated areas of the culture (centre) are larger and more flattened than those in areas of higher density. Cell debris is arrowed. $\times 150$. 

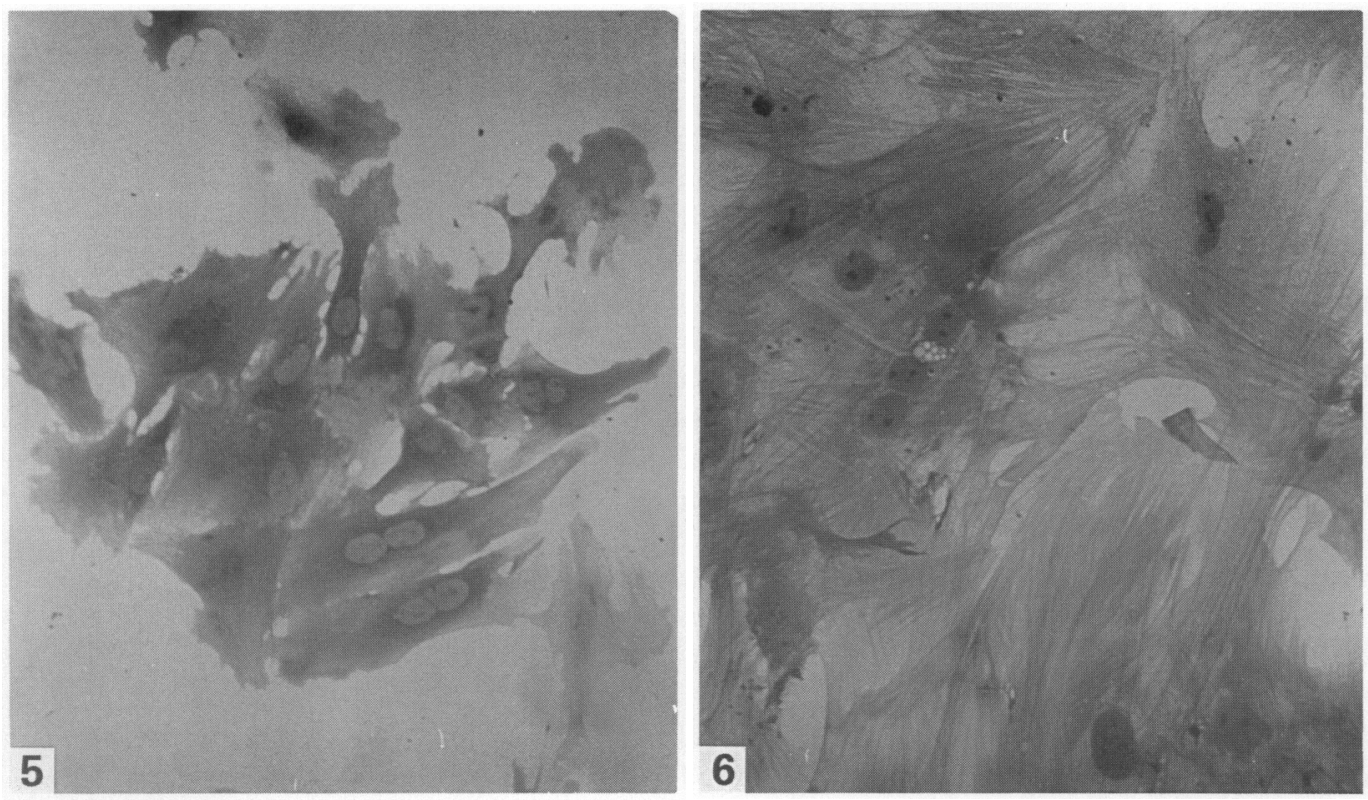

Fig. 5. A group of cells from Day 11 of pregnancy on Day 1 of culture. Note the size and shape of the nuclei in comparison to the cells in Fig. 3. $\times 150$.

Fig. 6. Cells from Day 11 of pregnancy on Day 21 of culture. Note the very thin nature and large size of the cells. $\times 150$.

\section{Discussion}

Altering the seeding density showed that inoculum size had no significant effect on subsequent survival of cells from Day 11 of pregnancy. The numbers of cells in these cultures only changed slightly over the culture period. Several studies have demonstrated that minimum seeding densities are required for cell survival and proliferation in culture (Earle et al., 1951; Todero \& Green, 1963) and previous reports of cultured endometrial cells have indicated that a minimum of $140 \mathrm{cells} / \mathrm{mm}^{2}$ is required (Bell \& Searle, 1981). It is apparent that cells from Day 11 of pregnancy can be maintained in a steady state at a much lower seeding density $\left(7 \mathrm{cells} / \mathrm{mm}^{2}\right)$. It is possible that cells from the fully differentiated decidua are more tolerant of suboptimal culture conditions, but preliminary studies (not included here) indicate that, at similar plating densities, cells from Day 6 of pregnancy are capable of an exponential increase in cell numbers.

During the oestrous cycle and the first days of pregnancy, the uterine stroma consists of a uniform population of fibroblast-like cells and is infiltrated by a small number of lymphocytes and macrophages (O'Shea et al., 1983). As the decidua develops, the range of cell types within it increases so that lymphocytes, macrophages, metrial gland and trophoblast cells in addition to a number of subpopulations of decidual cells can be distinguished (Bell, 1983; O'Shea et al., 1983; Welsh \& Enders, 1985). The increased complexity of the decidualized endometrium was reflected in the cell cultures; examination of the cells on the first day of culture revealed that while only two cell types were observed in cultures of tissue from Day 6 of pregnancy, a variety of types was seen in cultures derived from Days 11 and 16 (see Pippard, 1987, for details of the other cell types). The proportions of each type present in cultures of cells from the last two stages differed.

In cultures of cells from Day 6 of pregnancy, a homogeneous population of stromal cells was observed. At this stage of pregnancy, decidualization has been initiated but is confined to the 
subepithelial cells on the antimesometrial side of the lumen (Enders \& Schlafke, 1967), with the remainder of the stroma retaining the fibroblast-like appearance characteristic of undecidualized stroma. Thus a mixture of differentiated and undifferentiated stromal cells would be expected in endometrial tissue obtained at this stage of pregnancy. However, there was little variation in the morphology of the cultured cells which resembled those obtained from later stages of pregnancy, when few undifferentiated stromal cells would be expected. This indicated either that undifferentiated cells in vitro have a similar morphology to differentiated cells or that the trauma of tissue dissociation induced decidual changes in the stromal cells.

Stromal cells in cultures from each of the stages of decidual development resembled one another, being very large, flattened and stellate. In all cultures the size of the cells increased over the culture period. The nuclei increased in size and complexity to become extensively lobulated in later stages of the cultures. These changes were most marked in cells from Days 6 and 11, with less prominent changes in cells from Day 16. The development of lobulated nuclei in cultured cells has been observed by other workers (Vladimirsky et al., 1977; Sananes et al., 1978; Bell \& Searle, 1981); this reflects the appearance of the nuclei of decidualized cells in vivo (Krehbiel, 1937; Jollie \& Bencosme, 1965 ) and is probably due to an increase in ploidy, since nuclear size has been correlated to DNA content (Barlow \& Sherman, 1972). Development of the cell nuclei occurred in cells even from the fully differentiated (i.e. Day 11 of pregnancy) and regressing (Day 16 of pregnancy) decidua. There is no evidence that endoreduplication continues after differentiation of the cells in vivo and this may indicate that, in normal circumstances, a limit to DNA replication is imposed on the decidual cells.

The appearance of stromal cells in vivo explanted shortly after decidual cell induction has been described previously but the various accounts are not in agreement. Two distinct morphological types have been described, firstly very large, flattened, stellate cells (Vladimirsky et al., 1977; Bell \& Searle, 1981) and secondly smaller, spindle-shaped cells resembling fibroblasts (Sananes et al., 1978; Bell \& Searle, 1981). It has been postulated (Bell \& Searle, 1981) that this morphological difference is due to seeding density, with higher seeding densities giving rise to cells of the second morphological type. In the cultures described here, of cells from Day 6 of pregnancy, very low seeding densities were used and the cells initially resembled the flattened, stellate cells. Cell division, however, resulted in the development of areas of high cell density. The cells exhibited no contact inhibition and, in the densely populated areas, several layers of overlapping cells were seen. In these areas, the upper cells were less flattened and more fusiform in appearance, resembling the second morphological type noted by Sananes et al. (1978) and Bell \& Searle (1981) in cultures of high seeding density. The similarity seen here between cells in the less densely populated areas of the culture and those at the base of the multilayered areas indicate that the substrate on which the cells grow (i.e. glass or other cells, in this case) may also affect their morphology. Harris (1973) showed that the morphology of fibroblasts is affected by the 'wettability' of the substrate.

Observations by previous authors that death of cultured cells occurred after about 2 weeks (Vladimirsky et al., 1977; Sananes et al., 1978; Bell \& Searle, 1981) support the hypothesis of a 'programmed lifespan' for decidual cells. The results obtained here, however, showing that cells from Day 6 of pregnancy are still increasing in numbers up to at least Day 16 of culture (the equivalent of Day 22 of pregnancy), and that some cells can survive up to 42 days in culture, suggest that decidual cells are not governed solely by a 'programmed lifespan'. The possibility that the surviving cells were undifferentiated stromal cells rather than decidual cells must be considered, but the evidence from cultures derived from Day 11 of pregnancy, which were fully differentiated in vivo and which could also survive for a prolonged period in vitro, supports the theory that other factors affect the lifespan of decidual cells in vitro. The differences in cultured cells derived from the three stages of decidual development indicate that changes occur to the cells in vivo which decrease their viability in culture.

If decidual cells are not controlled by an inherent lifespan, other possibilities must be considered. There are several ways in which formation and regression of the decidua could be controlled. Since decidual morphology is similar in pregnant and pseudopregnant animals bearing 
artificially induced deciduomata, it appears that the conceptus has little influence on stromal development. It is possible that the embryo may fine-tune the uterine response, as subtle differences between naturally and artificially induced decidual development have been observed (Welsh $\&$ Enders, 1985). Paracrine or endocrine hormones could influence the decidua; for example, progesterone is necessary for maintenance of decidual tissue (Atkinson, 1944; Finn \& Pope, 1984) and a local withdrawal of progesterone could control cell death. Extensive cell-cell contacts are seen throughout the decidua (Finn \& Lawn, 1967; Kleinfeld et al., 1976; Welsh \& Enders, 1985), and these may be a site of communication between cells, mediating an orderly sequence of cell death.

I thank Dr Stephanie Ellington and Dr Denis New for helpful comments and suggestions. This work was supported by the MRC.

\section{References}

Atkinson, W.B. (1944) The persistence of deciduomata in the mouse. Anat. Rec. 88, 271-278.

Barlow, P.W. \& Sherman, M.I. (1972) The biochemistry of differentiation of mouse trophoblast: studies on polyploidy. J. exp. Morph. Embryol. 27, 447-465.

Bell, S.C. (1983) Decidualization and associated cell types: implications for the role of the placental bed in the maternal-fetal immunological relationship. $J$. Reprod. Immunol. 5, 185 194.

Bell, S.C. \& Searle, R.F. (1981) Differentiation of decidual cells in mouse endometrial cell cultures. $J$. Reprod. Fert. 61, 425-434.

Bridgeman, J. (1948) A morphological study of the development of the chorio-allantoic placenta of the white rat. $J$. Morph. 83, 195-225.

Bulmer, D. \& Dickson, A.D. (1961) The fibrinoid capsule of the rat placenta and the disappearance of the decidua. J. Anat. 95, 300-310.

Dickson, A.D. (1979) The disappearance of the decidua capsularis and Reichert's membrane in the mouse. $J$. Anat. 129, 571-577.

Earle, W.R., Sanford, K.F., Evans, V.J., Waltz, H.K. \& Shannon, J.E. (1951) The influence of inoculum size on proliferation in tissue cultures. J. natn. Cancer Inst. 12, 133-154.

Enders, A.C. \& Schlafke, S. (1967) A morphological analysis of the early implantation stages in the rat. Am. J. Anat. 120, 185-226.

Finn, C.A. \& Keen, P.M. (1962) Studies on deciduomata formation in the rat. J. Reprod. Fert. 4, 215-216.

Finn, C.A. \& Lawn, A.M. (1967) Specialized junctions between decidual cells in the uterus of the pregnant mouse. J. Ultrastruct. Res. 20, 321-327.

Finn, C.A. \& Pope, M. (1984) Vascular and cellular changes in the decidualized endometrium of the ovariectomized mouse following cessation of hormone treatment - a possible model for menstruation. J. Endocr. 100, 295-300.

Harris, A. (1973) Behaviour of cultured cells on substrata of variable adhesiveness. Expl Cell Res. 77, 285-297.

Hetherington, C.M. (1968) Induction of deciduomata in the mouse by carbon dioxide. Nature, Lond. 219, $863-864$.

Jollie, W.P. \& Bencosme, S.A. (1965) Electron microscopic observations on primary decidua formation in the rat. Am. J. Anat. 116, 217-236.

Kleinfeld, R.G., Morrow, H.A. \& DeFeo, V.J. (1976) Intercellular junctions between decidual cells in the growing deciduoma of the pseudopregnant rat uterus. Biol. Reprod. 15, 593-603.

Krehbiel, R.H. (1937) Cytological studies of the decidual reaction in the rat during early pregnancy and the production of deciduomata. Physiol. Zool. 10, 212-233.

O'Shea, J.D., Kleinfeld, R.G. \& Morrow, H.A. (1983) Ultrastructure of decidualization in the pseudopregnant rat. Am. J. Anat, 166, 271-298.

Pippard, D.F. (1987) Studies of rodent endometrial tissue in vitro and in vivo. Ph.D. thesis, University of Cambridge.

Sananes, N., Weiler, S., Baulieu, E-E. \& LeGoascogne, C. (1978) In vitro decidualization of endometrial cells. Endocrinology 103, 86-95.

Scott, J.N. \& Pendergrass, P.B. (1981) Scanning electron microscopy of the decidual stalk and decidua basalis in the mouse. Anat. Embryol. 162, 435-441.

Stewart, I. \& Peel, S. (1978) The differentiation of the decidua and the distribution of metrial gland cells in the pregnant mouse uterus. Cell Tiss. Res. 187, $167-179$.

Tobert, J.A. (1976) A study of the possible role of prostaglandins in decidualisation using a non-surgical method for the instillation of fluids into the rat uterine lumen. J. Reprod. Fert. 47, 391-393.

Todero, G.J. \& Green, H. (1963) Quantitative studies of the growth of mouse embryo cells in culture and their development into established cell lines. J. Cell Biol. 17, 299-313.

Velardo, J.T., Dawson, A.B., Olson, A.G. \& Hisaw, F.L. (1953) Sequence of changes in the uterus and vagina of the rat during prolongation of pseudopregnancy associated with the presence of deciduomata. Am.J. Anat. 93, 273-306.

Vladimirsky, F., Chen, L., Amsterdam, A., Zor, U. \& Lindner, H.R. (1977) Differentiation of decidual cells in cultures of rat endometrium. $J$. Reprod. Fert. 49, 61-68.

Welsh, A.O. \& Enders, A.C. (1983) Occlusion and reformation of the rat uterine lumen during pregnancy. Am. J. Anat. 167, 463-477.

Welsh, A.O. \& Enders, A.C. (1985) Light and electron microscope examination of the mature decidual cells of the rat with emphasis on the antimesometrial decidua and its degeneration. Am. J. Anat. 172, 1-29.

\section{Received 18 February 1987}

